Indonesian Journal of EFL and Linguistics

Vol. 4 No. 2, 2019

eISSN: 2503-4197, pISSN: 2527-5070

www. indonesian-efl-journal.org

\title{
Indonesian EFL Learners' Willingness to Communicate in the Instructional Context
}

\author{
Suci Nugrah Amalia \\ Universitas Sebelas Maret \\ e-mail: suci.nugrahamalia@gmail.com \\ Abdul Asib \\ Universitas Sebelas Maret Surakarta, Indonesia \\ e-mail: abdulasib@yahoo.com \\ Sri Marmanto \\ Universitas Sebelas Maret Surakarta, Indonesia \\ e-mail: marmanto@staff.uns.ac.id
}

\begin{abstract}
:
The principal goal of L2 education is to enhance learners' willingness to communicate (WTC). Hence, this survey study was undertaken with the purpose of exploring Indonesian EFL learners' WTC especially in a classroom context or the so-called Instructional WTC (IWTC) in order to know the conditions triggering their willingness and unwillingness to communicate using L2. This survey applied descriptive quantitative method where 100 EFL learners from three State Universities in Indonesia were involved as the respondents. The respondents are the English students of IAIN Curup Bengkulu, Universitas Sebelas Maret (UNS) Surakarta and Universitas Musamus Merauke Papua. Those universities represent three of five major islands in Indonesia. A questionnaire was distributed to the respondents in order to explore their WTC in six IWTC components comprising
\end{abstract}


Suci Nugrah Amalia, et al

communicative self-confidence, integrative orientation, situational context of L2 use, topical enticement, learning responsibility, and off-instruction communication. The findings revealed that group size, classroom environment, students' cohesiveness, familiarity to the topic, degree of topic preparation, classroom seating arrangement, gender, self-awareness, and familiarity with interlocutors were the factors that affected learners' WTC. Further studies are highly recommended to deeply explore the teaching activities done by teachers by considering the influential factors of learners' willingness and unwillingness to communicate as an effort to maximize their WTC.

Keywords: Indonesian EFL Learners, IWTC, L2 Classroom, WTC

\section{INTRODUCTION}

In second language (hereafter as L2) education, stimulating the students' willingness to take the opportunities to communicate is the ultimate goal (MacIntyre, Clement, D'ornyei, \& Noels, 1998). Therefore, the unsuccessful effort to lead students to be willing to communicate is considered the failure of L2 learning program. In this regard, as the facilitators, teachers play a critical role to create practical learning situations for the sake of supporting students to communicate. It is in light of that L2 learning in the aspect of willingness to communicate (WTC) is situated learning. Furthermore, it is believed that WTC results from the joint effect of both individual psychological conditions and situational variables (Kang, 2005; Pawlak, Wiertelak $\&$ Bielak, 2016). Teachers in this case take charge of facilitating the situational contextual factors such as creating group-work activities by considering the group sizes, interlocutors, topics, and cultural backgrounds as to promote students' WTC (Cao \& Philp, 2006; Kang, 2005). Furthermore, In Indonesian context, Prasetyanto, et al., (2019) proved that the teacher's reinforcement influence students WTC in case of confidence, interpersonal and intergroup motivation. In the classroom context, the aforesaid aspects of communication are crucial to support students to develop their communicative competence and their willingness to be actively engaged in communication. As explained in the Interaction Hypothesis, learners' communicative competence in L2 will improve due to the conversational adjustment that happens during communication.

Unfortunately, as English communication takes place in classroom learning, some learners who are not willing to communicate are still encountered. The preliminary study in some Indonesian EFL classrooms revealed that there are only few students who can actively engage in communication and take the opportunities to communicate using English, while other students remain to be silent. Prihartanti (2017) investigated the willingness of Indonesian EFL learners to engage in communication and their anxiety levels. It revealed that their willingness to communicate in English is very low where more than $68 \%$ of them indicated that their language anxiety affected their WTC. In this regard, their unwillingness is likely caused by several reasons such as the high level of language anxiety, the 
ineffective classroom environment, the low level of motivation, and etc. Moreover, there are still many aspects that may affect students' WTC in the classroom contexts such as communication confidence, teacher's reinforcement, classroom environment, motivation, learners' beliefs, and higher level of grit (Peng \& Woodrow, 2010; Prasetyanto, et al., 2019; Lee \& Hsieh, 2019). Hence, it is necessary for the teachers to give extra attention to a range of factors and sub-factors that probably affect students' willingness and unwillingness to engage in communication, to find the problems with respect to communication, and to deal with those problems.

Grounded in the foregoing condition as regards students' WTC, the present study then aims at exploring the EFL students' WTC, especially in the instructional context to seek information about the situation in which students are willing and unwilling to communicate. The results of this study are hopefully useful to provide teachers with information or insights about the condition of students' WTC along with the extent to which they are willing and unwilling to communicate. By knowing such information, it is expected that the teachers can get some benefits, further continue to develop situations driving students' willingness to communicate, and help find solutions to avoid the presence of the factors causing students to be unwilling to communicate. Moreover, the teachers can support and facilitate the students until they are willing to communicate in every context. As a result, the EFL learning in the classroom can be maximized to encourage students to have high WTC and to maintain students to always be motivated as well as enthusiastic about learning English done not only at school but also at home. This way can also trigger students to be autonomous learners.

\section{LITERATURE REVIEW}

\subsection{The Notion of WTC}

Although it is clearly understandable that people need to communicate, a question still arises especially regarding the reason why some people prefer to talk to others, while others might to some extent avoid any communication under the same condition. The foregoing is probably influenced by the personality variable that is called willingness to communicate (WTC) which is elucidated by McCroskey \& Richmod (1990) as the cause of why people diverge in their communicative behavior.

In the beginning, the theoretical notion of WTC was developed in the discursive area of native language (L1) use. It could be traced back to Burgoon (1976) who initially introduced the notion of unwillingness to communicate which was defined as the tendency to prevent verbal communication. Later, the unwillingness to communicate was re-hypothesized by McCroskey \& Baer (1985) who introduced WTC as the possibility to be engage in communication in the given opportunity. In their theoretical construct, they defined WTC as a personality trait that means the stable 
inclination to talk in various situations. Anchored in the personality trait hypothesis of WTC, MacIntyre, et al., (1998) brought the conception of WTC in the area of L2 WTC through the heuristic model comprising various variables that may influence L2 WTC, also known as the pyramid model. This model implies that WTC is not only caused by the personality trait attributes like self-confidence, communicative competence, personality such as introvert and extrovert, and others, but also influenced by situational variables. It is due to people' WTC is vary according to different situations (McCroskey \& Richmond, 1990).

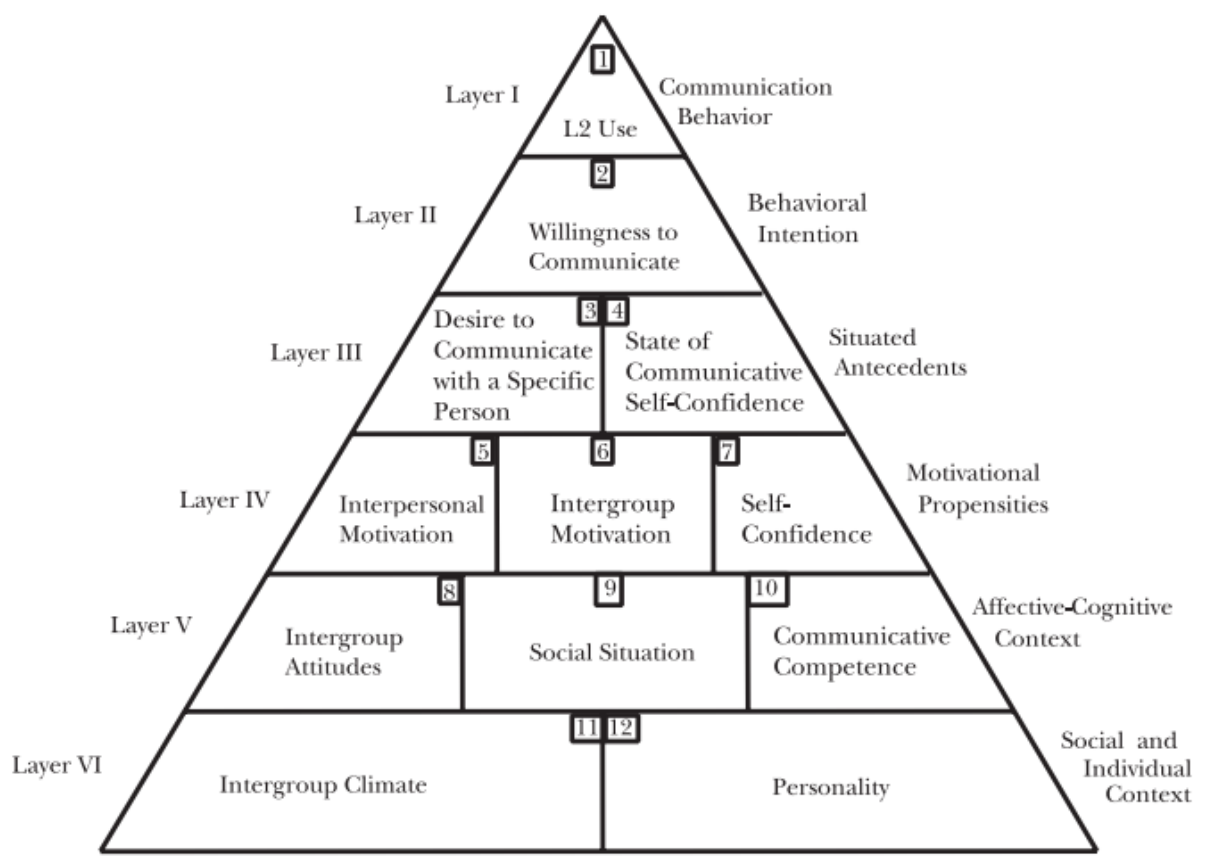

Fig. 1. Heuristic Model of Variables influencing WTC

In other words, the uncertainty in L2 WTC, which is more situational and has a more sophisticated manner in interaction such as social and political implication, makes it different from the L1 WTC. Hence, it is described to have both characteristics of trait and state levels. Peng \& Woodrow (2010) defined trait L2 WTC as a stable predisposition one has toward communication, meanwhile state L2 WTC is established in specific contexts. According to this, L2 WTC has been described as the willingness to engage into communication at a particular time with a specific person or people by using the second language (MacIntyre et al., 1998, p. 547). It represents some variables that may influence the foreign language learners' willingness to engage in L2 communication that varies significantly from individual to individual in different time and situations. Supporting this idea, Kang (2005) defines WTC as an individual's predisposition to be actively engaged in a communication according to particular situations covering conversational topics, interlocutors, situational contexts, and etc. 


\subsection{The Instructional WTC}

Resting upon the literature and relevant research of WTC, Khatib \& Nourzadeh (2015) developed WTC questionnaire in instructional context (IWTC) that is appropriate to be used in measuring learners' WTC in the classroom as what is explored in the present study. The IWTC includes six components. The first component is communicative self-confidence. Self-confidence is defined as an individual's belief in his ability to achieve goals, produce result, and competently perform task (Dörnyei, 2005). As it is integrated into communicative selfconfidence, it is defined as the learners' positive beliefs in their ability to receive and produce the message in L2 assuredly. The second component is integrative orientation. It is defined as learners' desire to recognize themselves in relation to L2 native speakers and L2 culture as the positive attitude they have towards the L2 culture (Gardner 1988). According to Dörnyei (2005), this kind of cultural motivation has been proven to be a strong predictor of language learning. The third component is the situational context of L2 use which refers to the temporary effect of situational variables in the instructional context towards students' communicative behavior. The fourth component is topical enticement. It is related to the power of the topic learned that could catch learners' interest and willingness to communicate. Students' familiarity and their background of knowledge about the learned topic are believed to entice their WTC. The fifth component is learning responsibility. Pursuant to the concept of socio-cognition, it is defined as learners' feeling that they are responsible to improve and develop their L2 competence by producing and understanding the L2 messages in communication (Kang, 2005). This is what is called learning by doing. The last component is off-instruction communication. It is defined as the willingness or awareness of learners to communicate using L2 when they are not under the instructional context.

Since this study measures learners' WTC in the classroom which means in the instructional context, the six IWTC components and the questionnaire developed by Khatib \& Nourzadeh (2015) are adapted to be the research framework and instrument.

Lots of studies addressing WTC have been done in different countries. Some studies investigated the interrelationship of individual and situational variables that influence one's WTC by providing the hypothesized L2 WTC model (Yashima, 2002; Peng \& Woodrow, 2010; Lee \& Hsieh, 2019). Those studies revealed that some variables such as communication confidence, motivation, and classroom environment strongly affect ones' WTC. Furthermore, many studies have been conducted to explore EFL learners' WTC, especially in L2 classroom context. Khatibi \& Zakeri (2014) investigated the learners' WTC across Different Contextand Receiver-types in Iranian context. Using 20 items of Self-assessment questionnaire, this study revealed that the EFL Iranian learners are more willing to communicate in the situation that they have experienced before like in group 
discussion and communicate with friends as the receiver-type they prefer most. In Indonesian context, Fadilah (2018) investigated a number of factors as dynamic complex systems and subsystems that influence students' WTC in the classroom. Social and classroom context, individual differences, linguistic competence and cultural context as the classroom systems were found to be the factors affecting learners' WTC. Different from the present study, it seeks to enhance the WTC literature especially in Indonesian context by investigating the EFL learners' WTC in the instructional context by using the validated questionnaire as the instrument. This study shows the level of students' WTC in some given contexts in classroom setting. Under this finding, the teachers can optimize the learning activities to trigger students' WTC in the target language so that the L2 education objectives can be achieved.

\section{RESEARCH METHODOLOGY}

In this study, the survey study was conducted to delve into the willingness to communicate (WTC) of Indonesian EFL learners. This survey involved students from three universities in Indonesia namely IAIN Curup Bengkulu, Universitas Sebelas Maret (UNS) Surakarta and Universitas Musamus Merauke Papua. Those three universities were chosen due to several considerations such as the researchers' accessibility and the location of universities that represented three of five major islands in Indonesia, namely Sumatra, Java, and Papua. The English Education Department students were chosen as the population in this study. In addition, this study used convenience sampling whereby there were $100(n=76$ female and $n=24$ male) respondents involved as the samples. In collecting the data, a questionnaire was distributed to every EFL learner taking part as the sample in order to know their WTC in the given contexts. The questionnaire of this study was taken and adapted from a relevant study conducted by Khatib \& Nourzadeh (2015) that developed and validated the questionnaire of WTC in instructional context (IWTC). There were 27 items in the questionnaire rated on the four-point Likert scale ranging from "would rather avoid" to "very much willing to." In analyzing the data, the descriptive analysis including the calculation of mean and standard deviation was undertaken in this study. Microsoft Excel 2016 which was one of the Microsoft Office applications was used to calculate the mean and standard deviation.

\section{FINDINGS AND DISCUSSION}

According to the result of the questionnaire, this study revealed some findings regarding the EFL learners' willingness to communicate in Indonesia that explicitly showed in what situation they were willing or unwilling to communicate mainly in the classroom context. The data associated with the findings are displayed in a table with some proper explanations corresponding to the table. The detailed findings are explained based on each of six IWTC components as explained in the literature review. 
Table: 1 The descriptive statistics for the items of IWTC components

\begin{tabular}{|c|c|c|}
\hline Items & Mean & SD \\
\hline $\begin{array}{l}\text { You are willing to speak even if other students laugh at your language } \\
\text { mistakes }\end{array}$ & 2.89 & 0.86 \\
\hline $\begin{array}{l}\text { You are willing to speak even if you know your classmates are better } \\
\text { than you at speaking English }\end{array}$ & 3.14 & 0.77 \\
\hline You are willing to give a presentation in front of your classmates & 3.22 & 0.81 \\
\hline $\begin{array}{l}\text { You are willing to speak even if your language mistakes are frequently } \\
\text { corrected by the teacher }\end{array}$ & 3.14 & 0.78 \\
\hline You are willing to talk in group-work language-learning activities & 3.31 & 0.75 \\
\hline $\begin{array}{l}\text { You are willing to have a group discussion about the marriage tradition } \\
\text { in English cultures }\end{array}$ & 2.87 & 0.80 \\
\hline $\begin{array}{l}\text { You are willing to talk about the lifestyle of English people in a whole- } \\
\text { class discussion }\end{array}$ & 3.02 & 0.85 \\
\hline $\begin{array}{l}\text { You are willing to talk to your classmates about the history of English } \\
\text { countries }\end{array}$ & 2.65 & 0.88 \\
\hline $\begin{array}{l}\text { You are willing to discuss cultural differences between English and } \\
\text { Indonesian people in a group }\end{array}$ & 3.13 & 0.82 \\
\hline You are willing to talk to your teacher about English literature & 2.8 & 0.82 \\
\hline $\begin{array}{l}\text { You are willing to speak more when a discussion is related to your own } \\
\text { personal experiences }\end{array}$ & 3.25 & 0.83 \\
\hline $\begin{array}{l}\text { You are willing to speak more when you are in the class of the same } \\
\text { language teacher over several terms }\end{array}$ & 3 & 0.71 \\
\hline $\begin{array}{l}\text { You are willing to find opportunities to speak no matter how crowded } \\
\text { the classroom is }\end{array}$ & 3.02 & 0.74 \\
\hline $\begin{array}{l}\text { You are willing to speak even if you are seated at the back of the } \\
\text { classroom }\end{array}$ & 2.69 & 0.91 \\
\hline You are willing to talk to your classmates about movies and series & 3.14 & 0.94 \\
\hline $\begin{array}{l}\text { You are willing to talk about great artists you know in a group } \\
\text { discussion }\end{array}$ & 3.14 & 0.86 \\
\hline You are willing to talk to your classmates about computer games & 2.62 & 1.02 \\
\hline $\begin{array}{l}\text { You are willing to talk about your favorite sport in a whole-class } \\
\text { discussion }\end{array}$ & 2.73 & 0.95 \\
\hline $\begin{array}{l}\text { You are willing to ask your classmate about the correct pronunciation of } \\
\text { a word }\end{array}$ & 3.12 & 0.87 \\
\hline $\begin{array}{l}\text { You are willing to ask another student to explain a grammatical point to } \\
\text { you }\end{array}$ & 3.26 & 0.86 \\
\hline $\begin{array}{l}\text { You are willing to ask your teacher to repeat what he or she has just } \\
\text { said if you did not understand it }\end{array}$ & 3.07 & 0.81 \\
\hline You are willing to raise your hand to ask or answer questions & 3.08 & 0.91 \\
\hline You are willing to talk to your classmates outside of the classroom & 3.15 & 0.77 \\
\hline $\begin{array}{l}\text { You are willing to talk to the student sitting next to you before the } \\
\text { teacher enters the classroom }\end{array}$ & 3.18 & 0.81 \\
\hline $\begin{array}{l}\text { You are willing to talk to your classmates when the teacher leaves the } \\
\text { classroom for a few moments }\end{array}$ & 3.01 & 0.82 \\
\hline You are willing to talk with your classmates about your weekends & 2.97 & 0.89 \\
\hline You are willing to talk to strange students from other classrooms & 2.66 & 0.92 \\
\hline
\end{tabular}


Resting upon the above table, concerning with communicative self-confidence as the first instructional WTC component, the finding (see items 1-5 in table 1) revealed that the learners had a higher level of self-confidence in talking in a group-work language-learning activity $(\mathrm{M}=3.31)$. Compared to other given situations that required the students to perform their English skill especially speaking in front of the whole classroom members, they felt more confident in talking in a group activity which might consist of fewer people. The finding as such fundamentally aligns with some studies who found that group size affects learners' WTC (Cao \& Philp, 2006; Lahuerta, 2014). The learners seem to prefer to have a group with an ideal number like three or four persons because such condition paves the way for giving them adequate opportunities to speak as well as to listen to, and it also potentially leads them to help each other during learning. In contrast, a lack of self-confidence is likely experienced by the learners when communicating with the whole class members.

Furthermore, regarding self-confidence, the students experienced language anxiety to communicate using the L2 (in this case, English) when other students laughed at the language mistakes they made while speaking $(M=2.89)$. It indicated that the students needed to comfort themselves with the support of their friends. This finding appears to support Peng \& Woodrow's (2010) study on students' cohesiveness that becomes one factor of classroom environment that affects learners' WTC in the classroom. Because learning is a process, mistakes then become the proof that students are trying. Thus, students' cohesiveness to help and support each other is needed. Following this finding, the teachers can maximize their role by designing more variations of language learning activities such as group work with the ideal number of members and role-play to trigger students' self-communicative confidence. The teachers also need to remind students that it is okay to make a mistake, and it is essential to tolerate others' mistakes as Khajavy et al., (2016) stated that the positive reinforcement as part of teachers' support can build the classroom condition.

For the second component of IWTC associated with integrative orientation, from the given situations (see items 6-10 in table 1), the students were obviously more willing to have a discussion about the cultural differences between English and Indonesian people in a group $(\mathrm{M}=3.13)$ compared to their willingness to communicate with their classmates about the history of English countries $(M=2.65)$. As an implication, grounded in the issue associated with the integrativeness or cultural motivation, the learners seem to be willing to talk about the topic of L2 community and culture as long as they have adequate backgrounds of knowledge related to the topic under discussion. It is in line with Eddy (2015) who found that task related factors such as the appropriate topic which fit to students' level of knowledge were significantly affect students' WTC. In the given situations, the learners tend to be more willing to talk about the differences between Indonesian and English cultures due to their shared prior knowledge with respect to those cultures such as the knowledge about 
customs and habits rather than that of English country history, the marriage tradition in English culture, or the English literature in which they have lack of historical knowledge. Concerning with this finding, Yashima (2002) reported that international posture affects students' WTC. The higher level of integrativeness ones have will strongly affect their readiness to interact with L2 language group. In addition, students' WTC was also affected by the group discussion model where there was less pressure compared with the situation when they were asked to talk about the English people's lifestyle in a whole-class discussion $(\mathrm{M}=3.02)$. In this regard, corresponding to integrative orientation that is strongly related to the target language social and cultural purpose, the teacher should design the materials and topics in which the students have adequate backgrounds of knowledge. Language learning is hoped to encourage students to speak up.

Appertaining to the third component of IWTC addressing about the situational context of L2 use, in the given situational contexts (see items 11-14 in table 1), it was found that the students were willing to speak in a discussion whose topic was related to their own experience $(M=3.25)$. Cao (2006) agreed that the degree of topic preparation affects one's WTC. In this case, where the students are asked to talk about their own experience, they will have greater confidence as the result of adequate knowledge and idea to talk. This point has also been discussed by Neer \& Kircher (1989) who reported that the learners have much of anxiety and feeling insecure about conveying the topic that they have less background of knowledge. In addition, Khatibi \& Zakeri (2014) stated that the students experience a lack of confidence to be engaged in communication in an unfamiliar situation. Hence, talking about personal experiences where the students know exactly the related stories will help them talk smoothly. As an implication, the teachers can prepare the discussion topics that are more oriented towards students' views, perceptions, or experiences.

In another situation regarding classroom organization, it was found that the students were prone to be unwilling to actively communicate when they were seated at the back of the classroom $(M=2,69)$. It revealed that students' WTC was influenced not only by the topics of discussion as well as the designed activities of languagelearning, but also by the classroom arrangement. In line with this finding, in his qualitative study, Peng (2007) reported that classroom organization influences L2 WTC. Therefore, the teachers may arrange the setting of students' seats in horseshoe arrangement (U shape) to avoid the unbalanced voice instruction. McCorskey \& McVetta (1978) introduced some classroom seating arrangements besides the conventional ones namely horseshoe arrangement and modular arrangement. However, the classroom arrangement should also be supported by the classroom interaction pattern. The teacher can maximize the classroom setting by appropriately design the interaction pattern to make sure that everyone has the same opportunity to speak up. In accordance with this issue, Vongsila \& Reinders (2016) proved that the 
frequency of students' talk is significantly affected by the classroom interaction pattern as it is a factor that influence their WTC.

Corresponding to the fourth IWTC component, topical enticement, the finding (see items 15-18 in table 1) revealed that the students were more willing to talk under the topics about movies and series of great artists $(M=3.14)$ compared to under discussion about the favorite sports $(M=2.73)$ and the computer games $(M=2.62)$. This finding revealed that the topic of discussion affected the learners' engagement in communication. This also aligns with some previous studies finding out that the familiarity and knowledge about the topic under discussion affect learners' WTC (Cao \& Philp, 2006; Cao, 2011; Peng, 2014; Wiertelak, 2015; Pawlak et al., 2016). It indicates that the more familiar the learners to the topic, the more ideas they can share. Furthermore, the finding also indicated that the factor of gender also contributed to learners' WTC. The topics of sports and computer games tended to have strong relation to male activities, so as a consequence, not all of female students were familiar with those topics, while 76 percent respondents of this study were female. On the other hand, the topic about movies was more general to be discussed. Such finding conforms to some empirical studies which reported that gender is one of inherently individual factors that affect one's WTC (Baker \& MacIntyre, 2000; MacIntyre et al., 2002). Thus, the teacher, in this case, should pay more attention in designing materials and choosing the topics that can promote students' willingness and avoid some particular topics that are not generally familiar with students or those correlated with gender sensitivity.

In respect of the fifth IWTC component, learning responsibility, the finding (see items 19-22 in table 1) showed that the learners had high self-awareness of their learning responsibility. They were willing to ask another student to explain a grammatical point to them $(M=3.26)$ as one of the fundamental basic competences in English learning. The adequate knowledge of grammar might lead students to effectively engage in L2 communication. In addition, the learners were also willing to ask their friends about the correct pronunciation of English words. Unfortunately, the students were less willing to directly raise their hands to answer the given questions $(M=3,08)$ and to ask the teachers to repeat what they had not yet understood $(\mathrm{M}=3,07)$. This condition showed that the students felt more comfortable to have peer assessment rather than directly ask the teachers to correct their mistakes. This finding is supported by Peng \& Woodrow (2010) who reported that students' cohesiveness as the factor that builds classroom environment affects learners' WTC in the classroom. The feelings of cohesiveness among the students make them psychologically closer in which they can help and support one another. This positive classroom environment can influence their learning behaviors (Dornyei $\&$ Murphey, 2003). Therefore, the teachers may design the activities or tasks where the students can help and support one another such as learning in pair or group. Regarding to this component, Lee \& Drajati (2019) found that informal digital learning of English (IDLE) helps students to improve their communicative 
competence which leads them to the higher level of WTC. In this case, the learners use the digital learning resources such as software, social media, blogs etc. autonomously as the media to improve their English skills. Thus, the teacher can maximize the IDLE to develop students' learning responsibility to be more independent learner.

Concerning with the sixth IWTC component, off-instruction communication, the finding (see items 23-27 in table 1) revealed that without teacher's instruction, the students were still willing to communicate using the target language. The students were willing to talk to other friends around them before the teacher entered the classroom $(\mathrm{M}=3.18)$. It became evident that students' self-awareness of developing their communicative skill and learning autonomously was not merely due to the teacher's instruction. On the other hand, the students tended to be unwilling to talk to strangers or other students from another classroom $(M=2.66)$. It can be understood that someone tends to avoid talking to the one he/she does not know well. This point is in line with Cao (2006) who found that the familiarity with interlocutor becomes one of the factors influencing learners' WTC. Hence, as an implication, the teachers can maximize language learning by giving homework or tasks that require students to continuously develop their communicative skill through having lots of practices with their friends.

\section{CONCLUSION}

This study has investigated the willingness of Indonesian EFL learners to communicate using the L2 (in this case, English) in an instructional context. Through several given conditions that rest upon the six components of IWTC covering communicative self-confidence, integrative orientation, the situational context of L2 use, topical enticement, learning responsibility, and off-instruction communication, this study has found out some conditions that trigger learners' willingness and unwillingness to communicate using the L2. As regards the data garnered from questionnaire, the findings indicate that the learners' WTC is strongly influenced by a variety of factors. First, group size and classroom environment are found to be the factors that influence the learners' communicative self-confidence. Most of the learners prefer to talk when incorporated into a group with the ideal number of members rather than in a whole-class discussion. Second, the learners have excellent willingness to communicate when dealing with integrative orientation. Therefore, their background of knowledge about the learned topics strongly influences their WTC. Third, in the situational context of L2 use, several factors such as the degree of topic preparation and the classroom organization for instance classroom seating arrangement affect the learners' WTC. The unsupportive sitting position is found to be one factor that affects learners' WTC. Fourth, the familiarity with the topic under discussion and stable variable like gender affect the learners' WTC under the topical enticement. Female students, for instance, tend to avoid talking about the topic with regard to sports and computer games. Fifth, 
Suci Nugrah Amalia, et al

students' cohesiveness becomes an influential factor in learners' learning responsibility. The learners prefer to ask their friends to correct their grammar and pronunciation rather than directly ask the teacher to correct their mistakes. Sixth, students' self-awareness and familiarity with the interlocutor influence learners' WTC in off-instruction communication. The learners seem to be willing to communicate using L2 without the teacher's instruction as long as their interlocutors are not strangers, or they are familiar with their interlocutors. Further studies are highly recommended to deeply explore teaching activities done by teachers by considering the influential factors of learners' willingness and unwillingness to communicate as an effort to maximize learners' WTC. Such studies can be meaningful references for English teachers in order to achieve the ultimate desirable goal of L2 education that is to successfully lead students to be willing to communicate.

Acknowledgements: The authors would like to express their deep gratitude to the participants of this study who have provided useful sources of data required to complete this study. In addition, the authors are particularly grateful for the assistance given by LPDP RI which has funded this study.

\section{REFERENCES}

Burgoon, J. K. (1976). The unwillingness-to-communicate scale: Development and validation. Communications Monographs, 43(1), 60-69.

Cao, Y. (2011). Investigating situational willingness to communicate within second language classrooms from an ecological perspective. System, 39(4), 468-479.

Cao, Y., \& Philp, J. (2006). Interactional context and willingness to communicate: A comparison of behavior in whole class, group and dyadic interaction. System, 34(4), 480-493.

Dörnyei, Z., \& Csizér, K. (2005). The effects of intercultural contact and tourism on language attitudes and language learning motivation. Journal of language and social psychology, 24(4), 327-357.

Dornyei, Z., \& Murphey, T. (2003). “ Group dynamics in the language classroom. Cambridge: Cambridge University Press.

Eddy-U, M. (2015). Motivation for participation or non-participation in group tasks: A dynamic systems model of task-situated willingness to communicate. System, 50, 43-55.

Gardner, R. C. (1988). "Attitudes and Motivation." Annual Review of Applied Linguistics 9: 135-148.

Kang, S. J. (2005). Dynamic emergence of situational willingness to communicate in a second language. System, 33(2), 277-292.

Khajavy, G. H., Ghonsooly, B., Hosseini Fatemi, A., \& Choi, C. W. (2016). Willingness to Communicate in English: A Microsystem Model in the Iranian EFL Classroom Context. TESOL Quarterly, 50(1), 154-180. 
Khatib, M., \& Nourzadeh, S. (2015). Development and validation of an instructional willingness to communicate questionnaire. Journal of Multilingual and Multicultural Development, 36(3), 266-283.

Khatibi, M. B., \& Zakeri, J. (2014). Iranian EFL learners' willingness to communicate across different context-and receiver-types. Procedia-Social and Behavioral Sciences, 98 (1). 932-939.

Lahuerta, A. C. (2014). Factors affecting willingness to communicate in a Spanish university context. International Journal of English Studies, 14(2), 39-55.

Lee, J. S., \& Drajati, N. A. (2019). Affective variables and informal digital learning of English: Keys to willingness to communicate in a second language. Australasian Journal of Educational Technology, 35(5).

Lee, J. S., \& Hsieh, J. C. (2019). Affective variables and willingness to communicate of EFL learners in in-class, out-of-class, and digital contexts. System, 82, 63-73.

MacIntyre, P. D., Clément, R., Dörnyei, Z., \& Noels, K. A. (1998). Conceptualizing willingness to communicate in a L2: A situational model of L2 confidence and affiliation. The Modern Language Journal, 82(4), 545-562.

McCorskey, J. C., \& McVetta, R. W. (1978). Classroom seating arrangements: Instructional communication theory versus student preferences. Communication Education, 27(2), 99-111.

McCroskey, J. C., \& Baer, J. E. (1985). Willingness to communicate: The construct and its measurement.

McCroskey, J. C., \& Richmond, V. P. (1990). Willingness to communicate: A cognitive view. Journal of Social Behavior and personality, 5(2), 19.

Neer, M. R., \& Kircher, W. F. (1989). Apprehensives' perception of classroom factors influencing their class participation. Communication Research Reports, 6(1), 70-77.

Pawlak, M., Mystkowska-Wiertelak, A., \& Bielak, J. (2016). Investigating the nature of classroom willingness to communicate (WTC): A micro-perspective. Language Teaching Research, 20(5), 654-671.

Peng, J. (2007). Willingness to communicate in the Chinese EFL classroom: A cultural perspective. In J. Liu (Ed.), English language teaching in China: New approaches, perspectives, and standards (pp. 250-269). London: Continuum.

Peng, J. E. (2015). L2 motivational self-system, attitudes, and affect as predictors of L2 WTC: An imagined community perspective. The Asia-Pacific Education Researcher, 24(2), 433-443.

Peng, J. E., \& Woodrow, L. (2010). Willingness to communicate in English: A model in the Chinese EFL classroom context. Language learning, 60(4), 834876.

Prasetyanto, B. T., Wibawani, D. A., Wardani, E. N., \& Drajati, N. A. (2019). Teacher's Reinforcements Affecting Students' Willingness to Communicate 
Suci Nugrah Amalia, et al

(WTC): A Photovoice in EFL Classroom. Indonesian Journal of EFL and Linguistics, 4(1), 57-71.

Prihartanti, N. (2017). Willingness to communicate in English: A case study of Indonesian university students. Kajian Linguistik Dan Sastra, 25(1), 71-81.

Vongsila, V., \& Reinders, H. (2016). Making Asian Learners Talk: Encouraging Willingness to Communicate. RELC Journal, 47(3), 331-347.

Yashima, T. (2002). "Willingness to Communicate in a Second Language: The Japanese EFL Context.” The Modern Language Journal 86 (1): 54-66. 